\title{
Ni(II) N-(2-Pyridylmethyl)-L-Alanine) Complex: Structural Diversity and Photoluminiscent Studies
}

\author{
Bridget N. Ndosiri1 ${ }^{*}$, Emmanuel N. Nfor ${ }^{2}$, Jérôme Marrot ${ }^{3}$, Aminou Mohamadou ${ }^{4}$, Justin Nenwa1 \\ ${ }^{1}$ Department of Inorganic Chemistry, Faculty of Science, University of Yaoundé I, Yaoundé, Cameroon \\ ${ }^{2}$ Department of Chemistry, Faculty of Science, University of Buea, Buea, Cameroon \\ ${ }^{3}$ Université de Versailles Saint-Quentin-en-Yvelines, Institut Lavoisier UMR 8180, Versailles, France \\ ${ }^{4}$ Université de Reims Champagne-Ardenne, Institut de Chimie Moléculaire de Reims (ICMR), CNRS UMR 7312, UFR des \\ Sciences Exactes et Naturelles, Bâtiment 18 Europol'Agro, Reims, France \\ Email: *ndosirin@yahoo.com
}

How to cite this paper: Ndosiri, B.N., Nfor, E.N., Marrot, J., Mohamadou, A. and Nenwa, J. (2020) Ni(II) N-(2-Pyridyl- methyl)-L-Alanine) Complex: Structural Diversity and Photoluminiscent Studies. Crystal Structure Theory and Applications, 9, 63-72.

https://doi.org/10.4236/csta.2020.94006

Received: October 17, 2020

Accepted: November 24, 2020

Published: November 27, 2020

Copyright () 2020 by author(s) and Scientific Research Publishing Inc. This work is licensed under the Creative Commons Attribution International License (CC BY 4.0).

http://creativecommons.org/licenses/by/4.0/

\begin{abstract}
A novel chiral Nickel (II) complex of N-(2-pyridylmethyl)-L-alanine (Hpyala) 1 has been prepared and structurally characterized by elemental analysis, FT-IR, UV-visible, TGA and single crystal X-ray diffraction techniques. Complex 1 crystallizes in an orthorhombic $\mathrm{P} 2{ }_{1} 2_{1} 2_{1}$ space group. The nickel (II) centre in the complex adopts a distorted octahedral geometry. This compound has been seen to exhibit structural diversity resulting from the number of lattice water molecules. The photoluminescent properties of this compound which have also been investigated, indicates the potential application in luminescence.
\end{abstract}

\section{Keywords}

Nickel (II) Complex, Chiral, Photoluminescent, X-Ray Diffraction

\section{Introduction}

The desire to rationally design and synthesize useful solid materials through the controlled assembly of molecular components, has led to a recent surge of interest in the concept of crystal engineering [1] [2] [3] [4]. So far, considerable progress has been achieved in tuning and predicting the mode of assembly and orientation of individual building blocks into structures with specific topologies and properties [5] [6] [7], but accurate prediction and control of the 3-D structure of molecular crystals and coordination polymers remains difficult. Reduced Schiff base ligands tend to form a suitable conformational and coordination en- 
vironment. They have been found to form more flexible and multidentate network complexes because of the reduction of the $\mathrm{C}=\mathrm{N}$ bond of the Schiff base which helps to overcome ligand stability [8] [9] [10]. In recent years, significant research interests have been devoted to coordination polymers with chiral helical structural motifs [6]. The preparation of chiral coordination complexes is a very well-established procedure and it dates back to Werner, who showed that the complex chirality depends on the formation of cis-coordination geometry around the metal ion with appropriate chelating/monodentate ligands. This can be understood based on the symmetry criteria that the absence of improper axis of rotation results in chirality [7]. Metal complexes of N-(2-pyridylmethyl)-amino acid derivatives with different spacers have been reported to have multiple attractive architectures including multidimensional and oligomeric structures with cavities, channels and chiral capsules owing to their robust hydrogen-bonding ability and inherent chirality [11]-[20]. In the pioneering work in these fields, $\mathrm{N}$-(2-pyridylmethyl)-alanine has been used to build the copper, cobalt and zinc complexes [20]. There have been few reports on new nickel (II) with $N$-(2-pyridylmethyl)-alanine in literature [10]. Furthermore, nickel (II) Schiff-base complexes have been reported to have promising applications for their luminescence [21] [22]. Herein, we report on a novel nickel (II) complex with pyridyl reduced Schiff-base ligand of amino acid derivatives [Ni(II)(L-pyala) $\left.)_{2}\right] \cdot 4 \mathrm{H}_{2} \mathrm{O}$, $\mathrm{L}-\mathrm{Hpyala}=\mathrm{N}$-(2-pyridylmethyl)-L-alanine, its synthesis, structural and photoluminescence properties. This article brings out some structural diversity as compared to a similarly reported nickel (II) complex in relation to the role of lattice water due to modified experimental conditions such as change in $\mathrm{pH}$ in directing the formation of supramolecular structures in the solid state [10]. In addition, its photoluminescence properties have been evaluated.

\section{Experimental}

\subsection{Materials}

All chemicals and solvents used for the synthesis were of reagent grade. Nickel acetate tetrahydrate (Aldrich), 2-pyridine aldehyde (Prolabo) and L-alanine (Prolabo) were used as received. The solvents, ethanol was dried and distilled according to standard methods.

\subsection{Analytical Methods}

Elemental analysis for carbon, nitrogen and hydrogen were carried out on a Fisons instrument 1108 CHNS-O. Infrared spectra were recorded on a Perkin-Elmer model IR-457 spectrometer and a spectrum 100 FT-IR Perkin Perkin-Elmer spectrometer, while X-ray diffraction was carried out with a CCD bidimensional diffractometer using monochromatic radiation, $\lambda\left(\mathrm{M}_{\mathrm{o}}-\mathrm{K}_{\alpha}\right)=$ $0.71073 \AA$, operating at $50 \mathrm{kV}$ and $40 \mathrm{~mA}$. TGA was recorded using a Mettler Toledo TGA/DSC1 SATR system while UV-visible spectrophotometer, HACH DR 3900, MARK Brucker. 


\subsection{Synthesis}

\subsubsection{Synthesis of Ligand}

The synthesis of the ligand was as described in literature [17].

\subsubsection{Synthesis of $\left[\mathrm{Ni}\left(\mathrm{C}_{9} \mathrm{H}_{11} \mathrm{~N}_{2} \mathrm{O}_{2}\right)_{2}\right] \cdot 4 \mathrm{H}_{2} \mathrm{O}$ (1)}

Pyala $(0.36 \mathrm{~g}, 2 \mathrm{mmol})$ in $10 \mathrm{~mL}$ water/ethanol mixture (1:1) was added drop wise to a $5 \mathrm{ml}$ aqueous solution of $\mathrm{Ni}\left(\mathrm{OOCH}_{3}\right)_{2} \cdot 4 \mathrm{H}_{2} \mathrm{O}(0.245 \mathrm{~g}, 1 \mathrm{mmol})$, while stirring magnetically at room temperature. Stirring continued for two hours. Suitable purple crystals for X-ray analysis were obtained from the solution by slow evaporation after two weeks. Yield 70\%; Anal. Calcd. For $\mathrm{C}_{18} \mathrm{H}_{30} \mathrm{NiN}_{4} \mathrm{O}_{8} ; \mathrm{C}$, 41.52; H, 4.12; N, 22.01; Found: C, 41.46; H, 4.07; N, 22.59.

\subsection{X-Ray Crystal Structure Determination}

The crystal structure of the complex was determined by single crystal X-ray diffraction on a Brucker $A P E X$-II using monochromatic MoKa radiation $(\lambda=$ $0.71073 \AA$ ) at a temperature of $198 \mathrm{~K}$ and integrated with SAINT-Plus program [23], and absorption corrections were carried out by multi-scan method by SADABS [24]. The Structure was solved by direct methods and refined against $\mathrm{F}^{2}$ by full-matrix least-squares techniques with SHELTL [25]. All non-hydrogen atoms were refined with anisotropic displacement parameters. The hydrogen atoms were included from calculated positions and refined riding their respective parent atoms with isotropic displacement parameters.

\section{Results and Discussion}

\subsection{Infra-Red Spectra}

The IR spectra of the ligand showed a characteristic weak absorption band at $2982 \mathrm{~cm}^{-1}$ due to $v(\mathrm{~N}-\mathrm{H})$ stretching of amines [26]. This band confirms the formation of imine $(-\mathrm{C}=\mathrm{N})$ group of Schiff bases which was reduced during the synthesis by $\mathrm{NaBH}_{4} / \mathrm{H}_{2} \mathrm{O}$ to the amine group $-\mathrm{N}-\mathrm{H}$. Furthermore the IR spectra of the ligand revealed a strong absorption band at $1672 \mathrm{~cm}^{-1}$ due to $v(\mathrm{C}=\mathrm{C}$, $\mathrm{C}=\mathrm{N}$ ) stretching of the pyridyl group [27]. This band in the metal complex shifted to $1577 \mathrm{~cm}^{-1}$ and $1597 \mathrm{~cm}^{-1}$. The decrease in wave number as a result of reduction in electron density around the $v(\mathrm{C}=\mathrm{C}, \mathrm{C}=\mathrm{N})$ bond of the ring, suggests the par ticipation of the pyridyl $v(\mathrm{C}=\mathrm{N})$ bond in the complexation through the nitrogen atom [28]. In addition the $\mathrm{Ni}(\mathrm{II})$ complex exhibited a very weak absorption band around $3288 \mathrm{~cm}^{-1}$ which suggests the deprotonation of the $v$ $(\mathrm{OH})$ bond and the participation of the oxygen atom in complexation [28].

\subsection{Crystal Structure of $\left[\mathrm{Ni}\left(\mathrm{C}_{9} \mathrm{H}_{11} \mathrm{~N}_{2} \mathrm{O}_{2}\right)_{2}\right] \cdot 4 \mathrm{H}_{2} \mathrm{O}(1)$}

The structure of 1 with atomic numbering scheme is shown in Figure 1. The Crystal data and structure refinement details for the title compound are summarized in Table 1 while selected bond lengths and angles are listed in Table 2. The $\mathrm{X}$-ray single crystal diffraction analysis reveals that complex 1 crystallizes in the 
Table 1. Crystal data and structure refinement for 1 .

\begin{tabular}{|c|c|}
\hline Compound & 1 \\
\hline Empirical formula & $\mathrm{C}_{18} \mathrm{H}_{30} \mathrm{~N}_{4} \mathrm{NiO}_{8}$ \\
\hline Formula weight & 489.17 \\
\hline $\mathrm{T}(\mathrm{K})$ & $198(2)$ \\
\hline Space group & $\mathrm{P} 22_{1} 2_{1} 2_{1}$ \\
\hline Wavelength $(\AA)$ & 0.71073 \\
\hline Crystal system & Orthorhombic \\
\hline \multicolumn{2}{|l|}{ Unit cell dimensions } \\
\hline $\mathrm{a}(\AA)$ & $9.7812(4)$ \\
\hline $\mathrm{b}(\AA)$ & $10.7564(4)$ \\
\hline$c(\AA)$ & $21.3721(8)$ \\
\hline$\alpha\left({ }^{\circ}\right)$ & 90 \\
\hline$\beta\left(^{\circ}\right)$ & 90 \\
\hline$\gamma\left({ }^{\circ}\right)$ & 90 \\
\hline Volume $\left(\AA^{3}\right)$ & $2248.57(15)$ \\
\hline $\mathrm{Z}$ & 4 \\
\hline $\mathrm{D}_{\mathrm{X}}\left(\mathrm{g} \cdot \mathrm{cm}^{-3}\right)$ & 1.445 \\
\hline$\mu\left(\mathrm{mm}^{-1}\right)$ & 0.91 \\
\hline $\mathrm{F}(000)$ & 1032 \\
\hline Crystal size $\left(\mathrm{mm}^{3}\right)$ & $0.24 \times 0.22 \times 0.14$ \\
\hline$\theta$ range $\left({ }^{\circ}\right)$ & $2.7-29.8$ \\
\hline Miller Index range & $\mathrm{V} 12 \leq \mathrm{h} \leq 13,-14 \leq \mathrm{k} \leq 15,-30 \leq 1 \leq 29$ \\
\hline Reflections collected & 179,527 \\
\hline Independent reflections $\left(\mathrm{R}_{\text {int }}\right)$ & $6570[\mathrm{R}(\mathrm{int})=0.030]$ \\
\hline Completeness to $\theta_{\max }(\%)$ & 99.9 \\
\hline Max. and min. transmission & 0.811 and 0.883 \\
\hline Data/restraints/parameter & $6570 / 7 / 322$ \\
\hline Goodness-of-fit (GOF) on F2 & 1.111 \\
\hline Final $\mathrm{R}$ indices $[\mathrm{I}>2 \sigma(\mathrm{I})]$ & $\mathrm{R} 1=0.019, \mathrm{wR} 2=0.048$ \\
\hline $\mathrm{R}$ indices (all data) & \\
\hline
\end{tabular}

Table 2. Selected bond lengths ( $\mathrm{A})$ and Bond angles $\left({ }^{\circ}\right)$ of 1 .

\begin{tabular}{cccc}
\hline \multicolumn{2}{c}{ Bond lengths } & \multicolumn{2}{c}{ Bond angles } \\
\hline Ni1-O1 & $2.0232(3)$ & O1-Ni1-O3 & $90.916(13)$ \\
Ni1-O3 & $2.0381(3)$ & O1-Ni1-N12 & $90.916(13)$ \\
Ni1-N12 & $2.0947(4)$ & O3-Ni1-N12 & $93.328(14)$ \\
Ni1-N1 & $2.0950(4)$ & O1-Ni1-N1 & $92.749(14)$ \\
\hline
\end{tabular}




\begin{tabular}{cccc} 
Continued & & & \\
\hline Ni1-N19 & $2.1030(3)$ & O3-Ni1-N1 & $95.509(13)$ \\
Ni1-N8 & $2.1177(3)$ & N12-Ni1-N1 & $171.737(15)$ \\
N12-C17 & $1.3398(6)$ & O1-Ni1-N19 & $170.037(13)$ \\
N12-C13 & $1.3444(6)$ & O3-Ni1-N19 & $82.608(18)$ \\
N1-C2 & $1.3405(6)$ & N12-Ni1-N19 & $79.887(14)$ \\
N1-C6 & $1.3447(5)$ & N1-Ni1-N19 & $95.083(13)$ \\
N19-C20 & $1.4860(5)$ & O1-Ni1-N8 & $82.324(13)$ \\
N8-C9 & $1.4882(5)$ & O3-Ni1-N8 & $169.686(13)$ \\
& & N12-Ni1-N8 & $94.792(14)$ \\
& & N1-Ni1-N8 & $80.106(14)$ \\
& & N19-Ni1-N8 & $105.075(13)$ \\
\hline
\end{tabular}

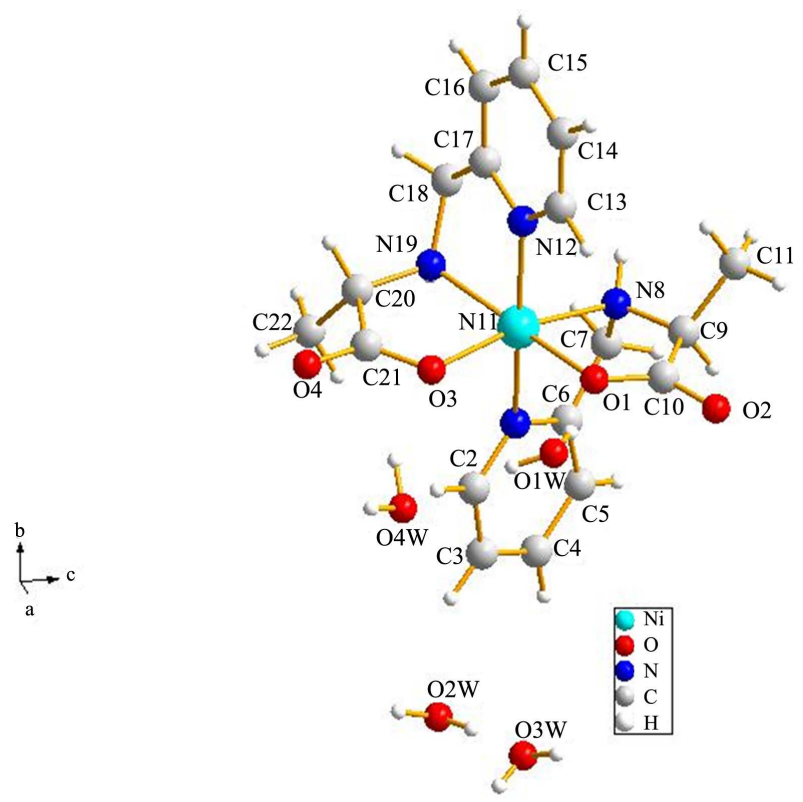

Figure 1. Coordination environment of $\mathrm{Ni}$ (II) center with atom labeling in 1 .

orthorhombic system $\mathrm{P} 22_{1} 2_{1} 2_{1}$ space group. The $\mathrm{Ni}(\mathrm{II})$ centre lying on the $\mathrm{C} 2$ axis $(\mathrm{x}, 1,1)$, has a distorted octahedral geometry, which is surrounded by two oxygen and four nitrogen donors from two monodentate carboxylate Ni1-O1, 2.0232 (3) $\AA$ A and Ni1-O3, 2.0381 (3) Á, two amino nitrogen atoms Ni1-N1, 2.0947 (4) $\AA$ Á, Ni1-N1, 2.0950 (4) Å and two pyridyl nitrogens Ni1-N19, 2.1030 (3) Å; Ni1-N8, 2.1177 (3) Å. The O1-Ni1-O3, O1-Ni1-N12, O3-Ni1-N12, O1-Ni1-N1 and O3-Ni1-N1 bond angles are $90.916(13)^{\circ}, 90.916(13)^{\circ}, 93.328$ $(14)^{\circ}, 92.749(14)^{\circ}$ and $95.509(13)^{\circ}$ respectively. These values are comparable to previously reported results of a similar nickel (II) complex with the same ligand having Ni-O bond distances in the range of 2.0496 (12) - 2.035 (2) $\AA$ and Ni-N bond distances in the range 2.0849 (13) - 2.110 (2) $\AA$ [10]. Furthermore the crystallographic studies revealed a different packing pattern with chiral channels 
runing parallel to the c-axis relative to that of a similar compund previously reported. This packing in 1 differs notably as evident in Figure 2 which could be attributed to the presence of four moelcules of water of crystallisation in the compound that facilitate hydrogen bonding formation.

\subsection{Thermal Stability}

The thermogravimetric analysis (TGA) of the complex was recorded with the TG curve shown in Figure 3. The first step decomposition at $25^{\circ} \mathrm{C}[7.88 \%$ weight loss (calculated, 11.92\%)] is attributed to the loss of three molecules of lattice water and the second decomposition at $110^{\circ} \mathrm{C}$ [2.50\% weight loss (calculated, $3.60 \%)$ ] which suggests the final loss of one molecule of lattice water, making a total loss of four water molecules of crystallization associated to the nickel (II) complex. The third decomposition at $270^{\circ} \mathrm{C}$ corresponding to $29.23 \%$ weight loss (calculated, $36.38 \%$ ) and the fourth decomposition at $330^{\circ} \mathrm{C}$ corresponding to $27.50 \%$ weight loss (calculated, $29.05 \%$ ), suggests the decomposition of the ligands. The final residue of $32.89 \%$ (calculated, 30.58 ) is attributed to the mixture of nickel oxides.

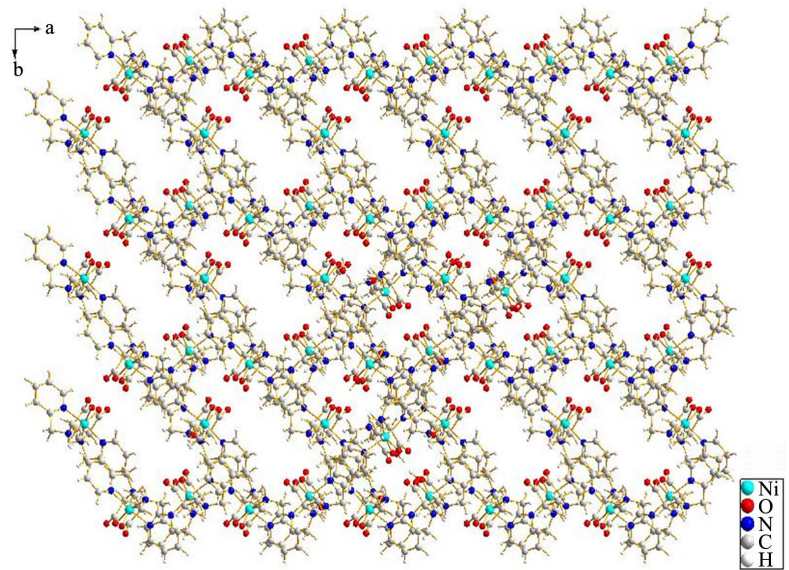

Figure 2. Packing of 1 along c-axis, showing a zigzag Ni(II) array of chiral channels.

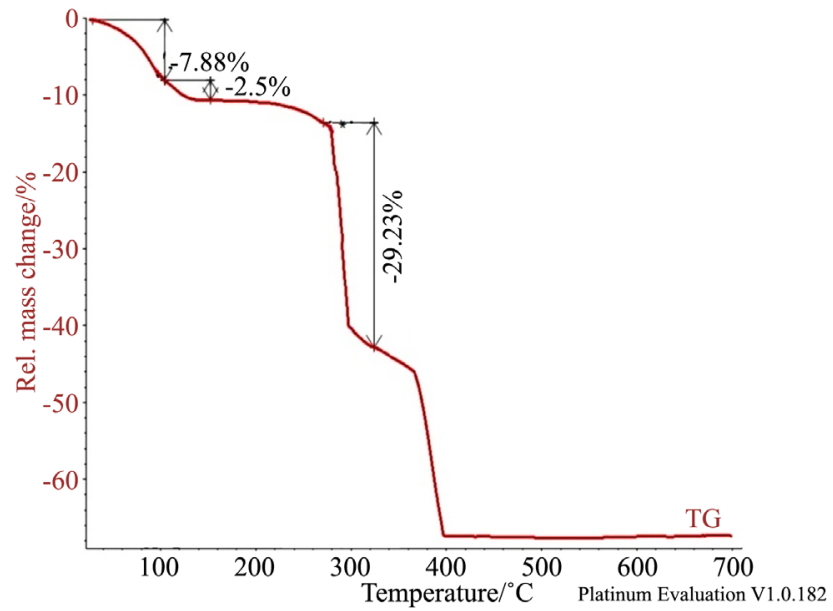

Figure 3. TGA thermogram for 1 . 


\subsection{UV-Visible Spectra}

The UV-visible spectra of 1 shows a small energy transition band at 320 - 331 $\mathrm{nm}$ and a weak broad absorption band in the range of $488-614 \mathrm{~nm}$ as shown in Figure 4. The small energy transition band at $320-331 \mathrm{~nm}$ in the nickel (II) spectra is attributed to the metal to ligand charge transfer (MLCT) transition in the nickel (II) complex and the weak broad band observed in the range of 488 $614 \mathrm{~nm}$ is presumably due to the spin allowed d-d transition $\left({ }^{3} \mathrm{~A}_{2 \mathrm{~g}} \rightarrow{ }^{3} \mathrm{~T}_{2 \mathrm{~g}}\right.$ (F) which is characteristic of an octahedral geometry around the nickel (II) atom [29].

\subsection{Photoluminescent Behavior of Compound}

The photoluminescent (PL) property of the complex (1) was investigated in the solid state at room temperature. The PL curve shown in Figure 5 showed strong fluorescent emission at $442 \mathrm{~nm}$. This was obtained when the complex was excited at $325 \mathrm{~nm}$. In order to understand the nature of the emission, we examined the PL property of the free ligand found that the strongest emission peak is at 391 and $432 \mathrm{~nm}$. Therefore the luminescence of the complexes May be attributed to metal to ligand charge transfer (MLCT) or ligand to metal charge transfer (LMCT) [10] [30] [31]. These observations suggest that the compound may be good a candidates for potential photoactive and in the preparation of optical.

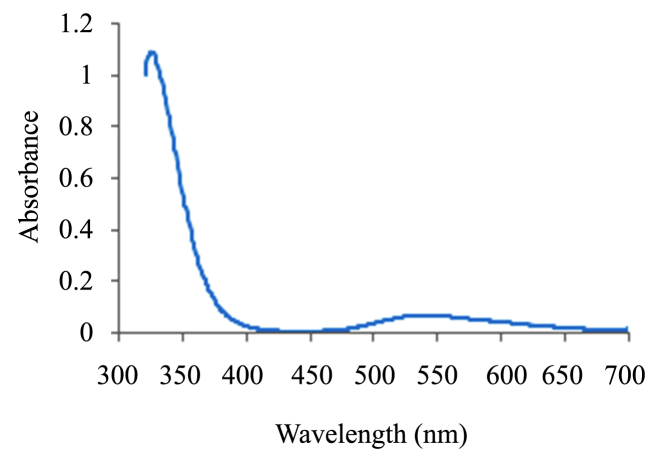

Figure 4. UV-visible spectra of $\mathrm{Ni}(\mathrm{II})$ complex.

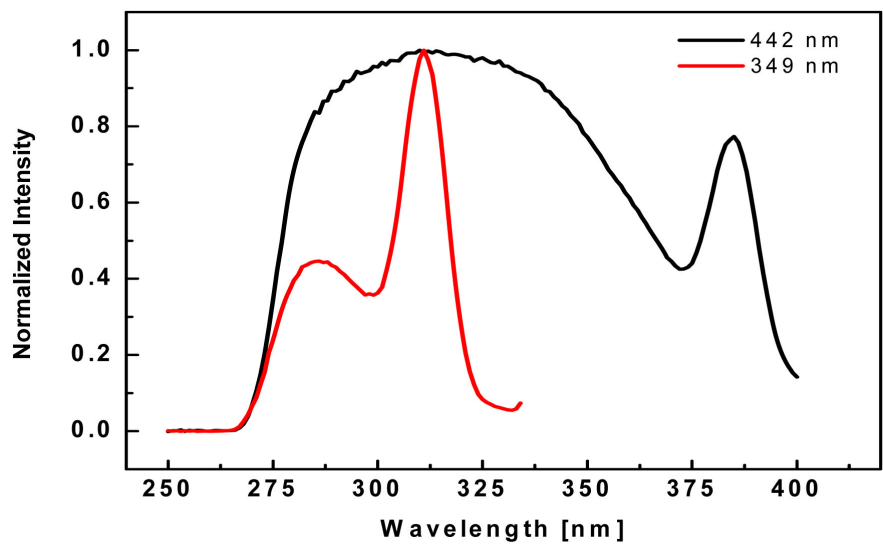

Figure 5. Solid state emission spectra of complex 1. 


\section{Conclusion}

A novel $\mathrm{Ni}$ (II) coordination polymer of $\mathrm{N}$-(2-pyridylmethyl)-(L)-alanine (Hpyala) has been obtained and the structure compared with that of a similar compound previously reported. The structural diversity of the compound compared with that previously reported is as a result of a difference in crystal water due to the modification of the experimental conditions such as $\mathrm{pH}$ in directing the formation of supramolecular structures in the solid state. Compound (1) crystallizes in the orthorhombic system with chiral space group, $\mathrm{P} 22_{1} 2_{1} 2_{1}$. The diversity in the structure is seen in its packing along various axes.

\section{Acknowledgements}

The authors gratefully acknowledge Dr. Namanga Jude Eko, Scientist at OSRAM for the photoluminescence analysis.

\section{Conflicts of Interest}

The authors declare no conflicts of interest regarding the publication of this paper.

\section{References}

[1] Janiak, C. (2003) Engineering Coordination Polymers towards Applications. Dalton Transactions, 2003, 2781-2804. https://doi.org/10.1039/b305705b

[2] Subramanian, S. and Zaworotko M.J. (1994) Exploitation of the Hydrogen Bond: Recent Developments in the Context of Crystal Engineering. Coordination Chemistry Reviews, 137, 357-401. https://doi.org/10.1016/0010-8545(94)03008-E

[3] Moulton, B. and Zaworotko, M.J. (2001) From Molecules to Crystal Engineering: Supramolecular Isomerism and Polymorphism in Network Solids. Chemical Reviews, 101, 1629-1658. https://doi.org/10.1021/cr9900432

[4] Wang, R., Yuan, D., Jiang, F., Han, L., Gong, Y. and Hong, M. (2006) Anion Effect on the Structural Conformation of Tetranuclear Cadmium(II) Complexes. Crystal Growth \& Design, 6, 1351-1360. https://doi.org/10.1021/cg0505970

[5] Hazra, S., Sarkar, B., Naiya, S., Drew, M.G.B., Frontera, A., Escudero, D. and Ghosh, A. (2010) Self Assembled Molecular Complexes and Coordination Polymers of Cd(II) Hexamine and Monocarboxylates: Structural Analysis and Theoretical Studies of Supramolecular Interactions. Crystal Growth \& Design, 10, 1677-1687. https://doi.org/10.1021/cg901245z

[6] Han, M.-L., Duan, Y.-P., Li, D.-S., Xu, G.-W., Wu, Y.-P. and Zhao, J. (2014) A Series of Divalent Metal Coordination Polymers Based on Isomeric Tetracarboxylic Acids: Synthesis, Structures and Magnetic Properties. Dalton Transactions, 43, 17519-17527. https://doi.org/10.1039/C4DT01946F

[7] Das, L.K., Gomez-Garcia, C.J. and Ghosh, A. (2015) Influence of the Central Metal ion in Controlling the Self-Assembly and Magnetic Properties of 2D Coordination Polymers Derived from $\left[(\mathrm{NiL})_{2} \mathrm{M}\right]^{2+}$ Nodes $(\mathrm{M}=\mathrm{Ni}, \mathrm{Zn}$ and $\mathrm{Cd})\left(\mathrm{H}_{2} \mathrm{~L}=\right.$ Salen-Type di-Schiff Base) and Dicynamide Spacers. Dalton Transactions, 44, 1292-1302. https://doi.org/10.1039/C4DT02823F

[8] Ndosiri, B.N., Nono, K.N., Awawou, P.G., Nfor, E.N., Mohamadou, A., Marrot, J. and Ndifon, P.T. (2019) Structural and Photoluminescent Studies of Non- Centro- 
symmetric Manganese (II) N-(2-Pyridylmethyl)-(L)-Alanine) Dicyanamide. European Journal of Chemistry, 10, 267-272.

https://doi.org/10.5155/eurjchem.10.3.267-272.1914

[9] Ganguly, R., Sreenivasulu, B. and Vittal, J.J. (2008) Amino Acid-Containing Reduced Schiff Bases as the Building Blocks for Metallosupramolecular Structures. Coordination Chemistry Reviews, 252, 1027-1050.

https://doi.org/10.1016/j.ccr.2008.01.005

[10] Zhang, Q.-Q., Zhang, Z.-H., Qu, B.-H., Chen, Q. and He. M.-Y. (2014) Synthesis, Supramolecular Assemblies and Luminescence of Nickel(II) Complexes Based on a Series of N-(2-pyridylmethyl)amino Acid Derivatives. Inorganic Chimica Acta, 418, 59-65 https://doi.org/10.1016/j.ica.2014.04.006

[11] Meiske, L.A., Jacobson, R.A. and Angelici, R.J. (1980) Synthesis, Spectral Characterization and Molecular Structure of [N-(2-pyridylmethyl)-L-asparto] (L-phenylalinnato) cobalt(III) Trihydrate. Inorganic Chemistry, 19, 2028-2034.

https://doi.org/10.1021/ic50209a038

[12] Li, X., Liu, T., Hu, B., Li, G., Zhang, H. and Gao, R. (2010) Homochiral Supramolecular Compounds Constructed from Amino Acid Derivatives: Syntheses, Structures, Chiroptical, and Photoluminescence Properties. Crystal Growth \& Design, 10, 3051-3059. https://doi.org/10.1021/cg100163g

[13] Lou, B.-Y., Yuan, D.-Q., Gao, S.-Y., Wang, R.-H., Xu, Y., Han, L. and Hong, M.-C. (2004) A Chiral Supramolecular Architecture $\left[\mathrm{Cu}_{2}(4,4 \text {-bipyridine })_{2}(\text { sala })_{2}\right]_{\mathrm{n}} \cdot 4.5 \mathrm{nH}_{2} \mathrm{O}$ (sala=N-(2-hydroxybenzyl)-l-alanine Anion). Journal of Molecular Structure, 707, 231-234. https://doi.org/10.1016/j.molstruc.2004.07.025

[14] Alam, M.A., Nethaji, M. and Ray, M. (2005) Structural Characterization of an Enantiopure Hydroxo-Bridged Binuclear Iron(III) Complex with Empty One-Dimensional Helical Channels. Inorganic Chemistry, 44, 1302-1308.

https://doi.org/10.1021/ic049145n

[15] Alam, M.A., Nethaji, M. and Ray, M. (2003) Synthesis of a Self-Assembled Molecular Capsule that Traps Pyridine Molecules by a Combination of Hydrogen Bonding and Copper(II) Coordination. Angewandte Chemie International Edition, 42, 1984-1986. https://doi.org/10.1002/anie.200250591

[16] Vittal, J.J., Wang, X. and Ranford, J.D. (2003) Influence of the $\mathrm{Li}^{+}$on the Structure of the $\left.\left[\mathrm{Cu}_{3} \text { (phis) }\right)_{3}\right]^{3+}$ Cation. Inorganic Chemistry, 42, 3390-3392.

https://doi.org/10.1021/ic026311n

[17] Wang, X. and Vittal, J.J. (2003) Self-Assembly of a 1D Helical Coordination Polymeric Lead(II) Complex with $\mathrm{Pb} \cdots \mathrm{O}$ (perchlorate) $\cdots \mathrm{Pb}$ Scaffoldings. Inorganic Chemistry Communications, 6, 1074-1077.

https://doi.org/10.1016/S1387-7003(03)00184-9

[18] Wang, X. and Vittal, J.J. (2003) Nature of the Reactants and Influence of Water on the Supramolecular Assembly. Inorganic Chemistry, 42, 5135-5142.

https://doi.org/10.1021/ic0344970

[19] Wang, X., Ranford, J.D. and Vittal, J.J. (2006) One-Dimensional Coordination Polymers: $\mathrm{Cu}(\mathrm{II})$ and $\mathrm{Zn}(\mathrm{II})$ Complexes of N-(2-Pyridylmethyl)-Glycine and N-(2Pyridylmethyl)-Alanine. Journal of Molecular Structure, 796, 28-35. https://doi.org/10.1016/j.molstruc.2006.03.090

[20] Ama, T., Okamoto, K., Yonemura, T., Kawaguchi, H., Takeuchi, A. and Yasui, T. (1997) Tetranuclear Cobalt(III) Complex Having the Cubane $\mathrm{Co}_{4} \mathrm{O}_{4}$ Core: Synthesis and Structural Analysis of the Complex Containing (2-Pyridylmethyl)glycine. Chemistry Letters, 26, 1189. https://doi.org/10.1246/cl.1997.1189 
[21] Bhattacharjee, C.R., Das, G. and Mondal, P. (2003) Helical Ribbons of Cadmium(II) and Zinc(II) Dicarboxylates with Bipyridyl-Like Chelates-Syntheses, Crystal Structures and Photoluminescence. European Journal of Inorganic Chemistry, 2003, 2965-2971. https://doi.org/10.1002/ejic.200300061

[22] Bhattacharjee, C.R., Datta, C.C., Das, G., Chakrabarty, R. and Mondal, P.(2012) Induc tion of Photoluminescence and Columnar Mesomorphism in Hemi-Disc Salphen Type Schiff Base via Nickel (II) Coordination. Polyhedron, 33, 417-424. https://doi.org/10.1016/j.poly.2011.12.001

[23] (2003) SMART and SAINT Software Reference Manual Version 6.45, Bruker, Analytical X-Ray Systems, Inc., Madilson.

[24] Sheldrick, G.M. (2002) SADABS Version 2.10. A Software for Empirical Absorption Correction. University of Göttingen, Göttingen.

[25] Sheldrick, G.M. (1997) SHELX1.97. Program for Crystal Structure Refinement. University of Göttingen, Göttingen.

[26] Nfor, E.N., Husian, A., Majoumo-Mbe, F., Njah, I.N., Offiong, E.O. and Bourne, S.A. (2013) Synthesis, Crystal Structure and Antifungal Activity of Ni(II) Complex of a New Hydrazone Derived from Anti-Hypertensive Drug Hydralazine Hydrochloride. Polyhedron, 63, 207-213. https://doi.org/10.1016/j.poly.2013.07.028

[27] Baer, C. and Pike, J. (2010) Infrared Spectroscopic Analysis of Linkage Isomerism in Metal Thiocynate Complexes. Journal of Chemical Education, 87, 724-726. https://doi.org/10.1021/ed100284z

[28] Nfor, E.N., Esemu, S.N., Ayimele, G.A., Ededet, A.E., Iniama, G.E. and Offiong, E.O. (2011) Synthesis, Stereochemistry and Antimicrobial Activity of Copper(II) and Nickel(II) Complexes of 4-Phenylsemicarbazones. Bulletin of the Chemical Society of Ethiopia, 25, 361-370. https://doi.org/10.4314/bcse.v25i3.68668

[29] Akbari A. and Alinia, Z. (2013) Comparative Analysis of the Ni(II) Complex of the N, N'-Bis-(4-Hydroxysalicylidene)-1,2-Diaminoethane: Combined Experimental and Theoretical Study (DFT/PW91). Computational Research, 1, 19-26.

[30] Wen, L., Lu, Z., Lin, Z., Tian, H., Zhu, Q. and Meng, Q. (2007) Syntheses, Structures, and Physical Properties of Three Novel Metal-Organic Frameworks Constructed from Aromatic Polycarboxylate Acids and Flexible Imidazole-Based Synthons. Crystal Growth \& Design, 7, 93-99. https://doi.org/10.1021/cg0604982

[31] Christopher, L.C., Daniel, T.L. and Mark, F. (2007) Homo- and Heterometallic Coordination Polymers from the f Elements. CrystEngComm, 9, 15-26. https://doi.org/10.1039/B615696G 